\title{
Hygienisch-bakteriologische Untersuchungen des Küsten-Meerwassers im Bereich der Nordsee-Insel Sylt
}

\author{
J. Peters \\ Institut für Bioklimatologie und Meeresheilkunde der Universität Kiel; \\ WesterlandiSylt, Dentschland ( $B R D)$
}

\begin{abstract}
Sanitary bacteriological investigations of the coastal sea water around the North Sea island of Sylt. The island of Sylt is one of the most important recreation centres in the German part of the southern North Sea. As in other islands, the sewage of its several villages is led directly into the sea area ("Wattenmeer") between the island and the continental coast. During 1967 and 1968 the author examined whether there occurs any sewage pollution at the beaches of the open sea coast of Sylt. In order to estimate the water quality for bathing, the sanitary water control in Germany conventionally determines certain dhemical qualities as well as the general number of bacteria and the coli-titre of the water samples. Around the island of Sylt testing of 225 samples revealed that the upper limit of the bacteria number and of the coli-titre is not reached, neither at the open sea beach (bathing site), nor at the "Wattenmeer" coast, except in narrow districts left and right of the sewage outlets of the four sewage plants. By comparing the coli-titre of samples taken synchronously at different points of the coast, it was found that there is obviously a tidal drift of sewage-contaminated waters from the "Wattenmeer" to the open sea beach. Seasonal differences exist between general bacteria number and concentration of coli bacteria. It is concluded that the general number of bacteria depends on the concentration of organic matter in the water, while the absolute number of sewage bacteria can be estimated by means of the coli-titre only. The capacity of self-purification of sea water manifests itself in the abundance of its bacteria (mostly endemic marine forms). Bacterium coli and the coliform bacteria, however, are real sewage bacteria; their numbers must be carefully checked, since they indicate that human pathogenic bacteria may be present in the water as well.
\end{abstract}

\section{EINLEI'TUNG}

Die Nutzung des Küstenmeerwassers zum Baden einerseits und als AbwasserKlärelement andererseits hat in den letzten Jahren vielerorts stark zugenommen, so daß es dringend erforderlich ist, das Meerwasser im Bereich der Badeorte laufend hygienisch zu überwachen, um eine Infektionsgefährdung Badender durch Abwasserbestandteile zu vermeiden. In das Blickfeld der meeresbiologischen Forschung tritt damit das Problem des hygienisch zulässigen Grenzwertes meeresfremder Substanzen. Neben die rein naturwissenschaftliche Meeresmikrobiologie, die ihre Forschungen in fast allen Meeren der Welt mit subtiler Methodik treibt, drängt sich die nur praxisbezogene Wasserhygiene, deren Methoden vergleichsweise einfach sind und wegen ihrer routine- 
mäßigen Anwendung auch sein müssen. Es zeigt sich, daß eine enge Zusammenarbeit der Meereskunde mit der medizinischen Hygiene angesichts der massiven Zivilisationsschädigung der Meere dringend nötig ist.

Die sïdliche Nordsee wird vor allem durch die mit den Abwässern der küstennahen Großstädte verunreinigten Flüsse Elbe, Weser, Rhein und Themse derart mit meeresfremden Substanzen belastet, daß man die Nordsee schon als "Mülleimer" der Anliegerstaaten bezeichnet hat. Dieses Schlagwort wird in seiner Anschaulichkeit dadurch bestätigt, daß beispielsweise der ausgefaulte Klärschlamm der großen Hamburger Kläranlage Köhlbrandhö̈t regelmäßig mit Kähnen in die Gegend des Feuerschiffs Elbe I vor der Elbmündung gebracht und dort versenkt wird. Welches Ausmaß die Verunreinigung am Ende der 60er Jahre erreicht hat, mögen einige Angaben aus der diesbezüglichen meeresbiologischen Literatur zeigen:

Aus Untersuchungen von GuNKel (1963) und RHEINHEIMER (1968) über die bakteriologischen Verhältnisse in der Deutschen Bucht geht hervor, daß die Keimzahlen zwischen den Flußmündungen und Helgoland ca. zehnmal höher sind als in der übrigen südlichen Nordsee. Auch im Sediment dieses stark belasteten Seebereiches wurden von HiCKel \& Gunkel (1968) abnorm hohe Balsteriendichten festgestellt, und WeYLAND (1967), der das Sediment im Mündungsgebiet der Weser untersucht hat, fand hier regelmäßig coliforme Bakterien, welche geradezu als Abwasserindikatoren bzw. als Indikatoren frischer fäkaler Verunreinigung gelten. Abwassereinflüsse schließlich konnten von KAYSER (1968) weit über Helgoland und Amrumbank hinaus nachgewiesen werden.

Über das Wasser vor der schleswig-holsteinischen Westküste im Bereich der Inseln und Halligen lagen bisher noch keine entsprechenden bakteriologischen und chemischen Untersuchungen vor. In diesem Seegebiet, das sehr starken sommerlichen Fremdenverkehr aufweist, besteht im Sommer ein erhöhter Abwasseranfall. Da die Inseln Sylt, Föhr und Amrum ihre Abwässer (nach mechanischer Vorklärung in kommunalen Kläranlagen) dem Wattenmeer zur biologischen Klärung zuführen, bedeutet dies eine erhöhte Abwasserbelastung des umgebenden Meeres im Sommer. Ziel der Arbeit war es daher, den Gehalt an Bakterien und speziell coliformen Abwasserbakterien des Meerwassers im Bereich der Insel Sylt zu untersuchen.

\section{UNTERSUCHUNGSGEBIET UND METHODIK}

Die Insel Sylt hat den stärksten Fremdenverkehr an der deutschen Nordseeküste. Gebadet wird im Sommer vor allem an dem ca. $40 \mathrm{~km}$ langen Weststrand der Insel, aber auch an einigen Abschnitten des wattseitigen Strandes. Die Abwässer der Inselorte werden in fünf Kläranlagen mechanisch und außerdem zum Teil halbbiologisch vorgeklärt und dann ins Wattenmeer, das zwischen der Insel und dem Festland liegt, abgeleitet (vgl. Abb. 1). Eine dieser Anlagen, die größte (Nr. IV), entwässert in eine $5,6 \mathrm{~km}^{2}$ große Wattenbucht, die durch einen Damm vom übrigen Watt getrennt ist (Rantum-Becken). Die auf Sylt anfallenden Abwassermengen sind für das Jahr 1967 in Tabelle 1 zusammengestellt worden.

Die Wasserproben wurden stets von der Wasseroberfläche entnommen unter Be- 
nutzung von sterilisierten Flaschen mit $500 \mathrm{~cm}^{3}$ Inhalt. Die Proben kamen in jedem Falle spätestens vier Stunden nach ihrer Entnahme zum bakteriologischen Ansatz; Parallelansätzte erfolgten nicht. Die Methodik der Meerwasseruntersuchung entsprach den Vorschriften der „Deutschen Einheitsverfahren zur Wasser-, Abwasser- und Schlammuntersuchung" (3. Auflage, 1960), welche zur hygienisch-bakteriologischen Wasserbeurteilung die Bestimmung der Keimzahl pro Milliliter und die Bestimmung des "Colititers" fordern und dazu die Arbeitsweise einschließlich der Re-

Tabelle 1

Daten uber die Sylter Kläranlagen im Sommer und Winter 1967.

(Nach amtlichen Angaben der Kommunalbehörden von Sylt)

\begin{tabular}{|c|c|c|c|c|c|}
\hline \multirow{2}{*}{$\begin{array}{l}\mathrm{Nr} \text { in } \\
\text { Abbil- } \\
\text { dung } 1\end{array}$} & \multirow[t]{2}{*}{ Ort } & \multicolumn{2}{|c|}{$\begin{array}{l}\text { Zahl der die Anlagen pro } \\
\text { Tag nutzenden Personen }\end{array}$} & \multicolumn{2}{|c|}{$\begin{array}{l}\text { Täglich geklärte Ab- } \\
\left.\text { wassermenge (in } \mathrm{m}^{3}\right)\end{array}$} \\
\hline & & Winter & Sommer & Winter & Sommer \\
\hline I & List & 2500 & 8000 & 341 & 640 \\
\hline II & Kampen & 1640 & 6200 & \multicolumn{2}{|c|}{$\begin{array}{c}260 \\
\text { (Mittelwert) }\end{array}$} \\
\hline III & $\begin{array}{l}\text { Wenningstedt } \\
\text { Braderup }\end{array}$ & 2500 & 6500 & 260 & 800 \\
\hline IV & $\begin{array}{l}\text { Westerland } \\
\text { Rantum }\end{array}$ & 13000 & 35000 & 2384 & 3480 \\
\hline V & Hörnum & 1280 & 4000 & 130 & 533 \\
\hline \multicolumn{2}{|c|}{$\begin{array}{l}\text { Addition der Beträge der } \\
\text { Anlagen I, II, III und V }\end{array}$} & 7920 & 24700 & 991 & 2233 \\
\hline \multicolumn{4}{|c|}{ Tägliche Abwassermenge (Mittelwert von Sommer und Winter) } & \multicolumn{2}{|c|}{1602} \\
\hline \multicolumn{4}{|c|}{ Abwassermenge des Jahres 1967} & \multicolumn{2}{|c|}{583730} \\
\hline
\end{tabular}

zepturen der anzuwendenden Nährmedien angeben. Von diesen Vorschriften wurde in den hier besprochenen Untersuchungen nur insofern abgewichen, als das Nährmedium zur Keimzahlbestimmung nicht der Standard-Süßwasser-Pepton-Agar war, sondern der spezielle Meerwasser-Pepton-Hefe-Agar „2216 E“ nach ZoBELL, der in der Meeresmikrobiologie weit verbreitet ist und erfahrungsgemäß aus Meerwasserproben höhere Gesamtkeimzahlwerte bringt als es ein Süßwassernährboden kann. Im übrigen aber wurde nach den oben genannten Richtlinien vorgegangen:

(a) Keimzahl/ml (Zahl der aeroben, heterotrophen, proteolytischen Bakterien): Einguß-Mischverfahren in Petrischalen, Bebrütung $48 \mathrm{Std}$ bei $22^{\circ} \mathrm{C}$. Dieses Verfahren entspricht auch den Angaben von Gunkel \& Rheinhemer (1968).

(b) Coliformentiter und Colititer: Eine Reihe von Reagenzgläsern wird mit je $10 \mathrm{ml}$ Milchzucker-Nährbouillon gefüllt, dann werden dekadisch abgestufte Probewassermengen (von $100 \mathrm{ml}$ im ersten Glas bis $0,001 \mathrm{ml}$ im letzten Glas) zugesetzt. Nach 48stündiger Bebrütung bei $37^{\circ} \mathrm{C}$ erfolgt die Ablesung, wobei dasjenige Röhrchen mit der kleinsten Probewassermenge, welches noch die charakteristische, durch Colibakterienwachstum bedingte Gasbildung $\left(\mathrm{CO}_{2}\right.$ und $\mathrm{H}_{2}$; Gasfangröhrchen nach DURHAM waren zuvor beim Autoklavieren in die Nährbouillon versenkt worden) 


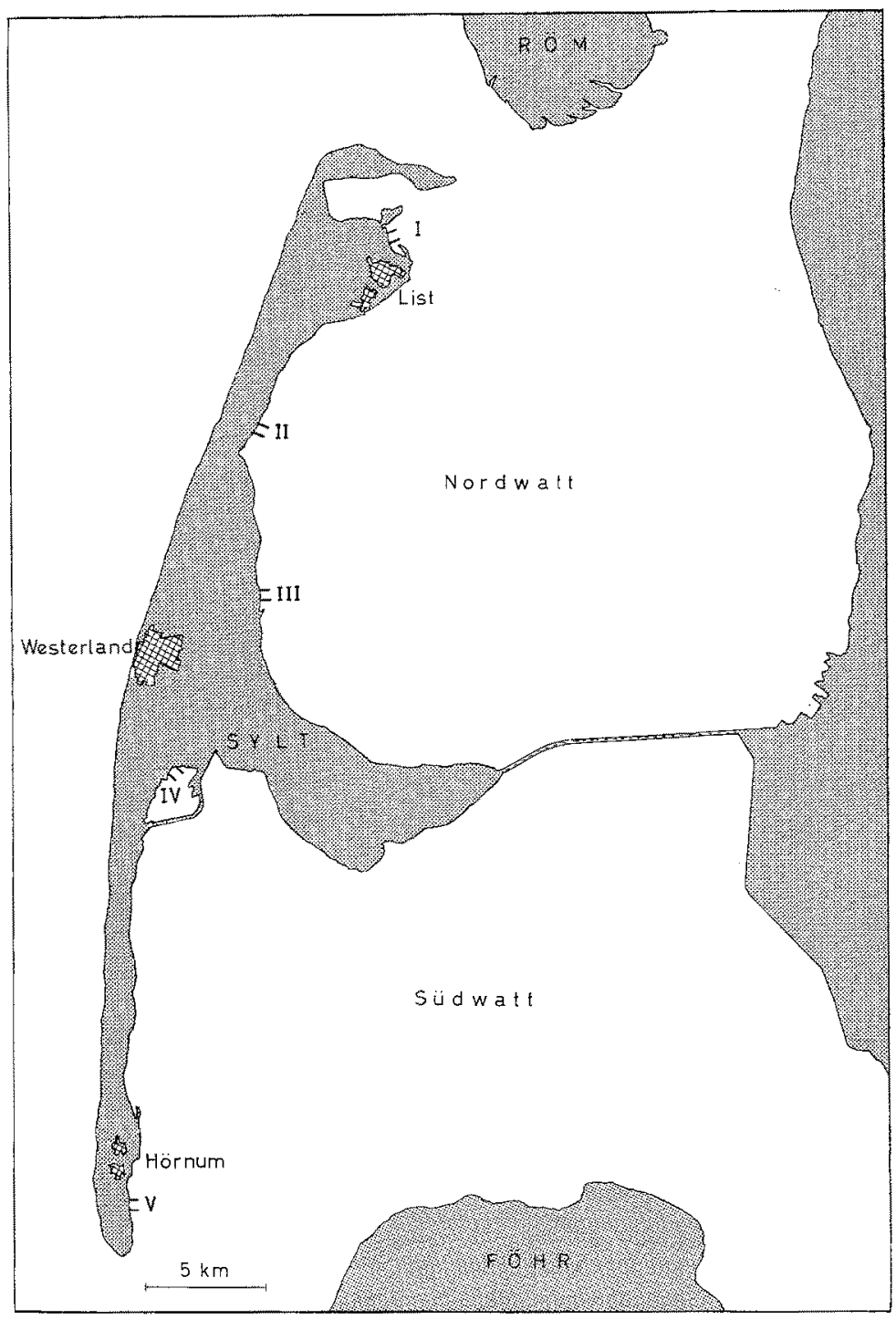

Abb. 1: Die Sylter Kläranlagen mir den Abflüssen des vorgeklärten Abwassers ins Wattenmeer. Die Anlage IV ist seit 1969 vergrößert und klärt jetzt die Abwässer der Gemeinden Westerland, Rantum, Tinnum und Keitum. Bei der Mittelwertberechnung in Tabelle 1 wird sie nicht berücksichtigt, weil sie nicht ins freie Watt, sondern in das abgedämmte Rantum-

Becken entwässert, so daß sie zur Abwasserbelastung des Meeres um Sylt nicht beiträgt

zeigt, den "Coliformentiter" angibt. Dann wurden - weiterhin streng im Sinne der "Deutschen Einheitsverfahren" - die vorliegenden Coli-Typen (nach WILSON 1935, vgl. SCHUBER T 1956) biochemisch differenziert, wobei schließlich diejenige kleinste Probewassermenge, aus der noch "obligat fäkale Colitypen" gezüchtet werden konnten, den im hygienischen Sinne mäßgebenden "Colititer" angab. Im folgenden wird jedoch 
nur von den gefundenen Coliformentitern berichtet, da im Küstenmeerwasser zunächst der Grad der allgemeinen Abwasserbelastung mehr interessiert als der Grad der fäkalen Abwasserbelastung.

Als eine weitere Maßzahl der Abwasserbakteriendichte kann die "Endo-Zahl“ dienen. Diese gibt die in $1 \mathrm{ml}$ Wasser enthaltene Anzahl solcher Keime an, welche den Milchzucker des Endo-Agars* unter Säurebildung vergären und als rote Kolonien wachsen; zu ihnen gehören die Coliformen, die als Abwasserindikatoren gelten. Vielfach wird diese Zahl als Colizahl verstanden, obwohl die Colibakterien sich zuverlässig nur zu erkennen geben dadurch, daß sie außer Säure auch Gas aus dem ihnen angebotenen Milchzucker bilden; auf dem Nachweis der Gasbildung aber beruht der Coliformentiter, so daß nur er die Coliformen ausschließlich erfaßt. Durch Bestimmung beider Parameter nebeneinander läßt sich beurteilen, ob die Endo-Zahl der Coliformenzahl wenigstens proportional ist. Der Ansatz zur Bestimmung der Endo-Zahl geschah so, daß $10 \mathrm{ml}$ des Probewassers durch ein Membranfilter gesaugt wurden; dieses wurde dann auf eine Endo-Agar-Platte gelegt und $48 \mathrm{Std}$ bei $37^{\circ} \mathrm{C}$ bebrütet. Nach Zählung der roten Kolonien und Reduktion ihrer Anzahl auf $1 \mathrm{ml}$ Probewasser ergab sich die Endo-Zahl.

\section{ERGEBNISSE}

Es folgen nun - tabellarisch zusammengefaßt - Mittelwerte der Keimzahl, der Endo-Zahl und des Coliformentiters (nicht des Fäkal-Colititers), wie sie im Sylter Seebereich im Winter 1967/68 und im Sommer 1968 gefunden wurden (Tab. 2). Die Errechnung der aufgeführten Beträge erfolgte als einfaches arithmetisches Mittel, bzw. bei den Titerwerten anhand yon Summen-Prozent-Kurven als 50-0/0-Werte.

Es handelt sich um Mittelwerte von 58 Proben aus dem offenen Meer westlich Sylt, 125 Proben vom Weststrand und 40 Proben vom Wattufer. Die hygienischen Grenzwerte für die Zulässigkeit als Freibadwasser (Keimzahl 10000/ml, Colititer $0,01 \mathrm{ml}$; Richtwerte des Kieler Hygiene-Instituts; siehe auch Carlson 1966) sind in keiner der 223 Proben erreicht oder überschritten. Die Endo-Zahl verhält sich nicht proportional der im Titerverfahren gemessenen Coliformenkonzentration, so daß es nicht gerechtfertigt erscheint, bei ihr von einer Colizahl zu sprechen. Hinsichtlich der Unterteilung der Befunde nach Winter- und Sommerwerten ist folgendes zu erkennen: Die Keimzahl ist in Wasserbereichen, die geringe Bakterienkontamination und geringen Bakterien-Nährstoffgehalt aufweisen, im Sommer niedriger als im Winter, dagegen am Wattufer im Sommer höher. Ahnlich ist es mit der Endo-Zahl. Die Coliformenkonzentration (umgekehrt proportional dem Coliformentiter) dagegen ist in der freien See und am Wattufer im Sommer niedriger als im Winter.

Berücksichtigt man einerseits, daß nach vielfach bestätigter meeresmilkrobiologischer Erkenntnis (CARlucci \& Pramer 1959, Rheinheimer 1968, VaCCaro 1950) die Bakterizidie des Meerwassers gegenüber Fremdkeimen im Sommer größer ist als im Winter, und andererseits, daß die Kontamination des Sylter Wattenwassers mit AbBakterien).

* Milchzucker-Pepton-Agar nadh ENoo (Indikator-Nährboden für milchzuckerspaltende 
Tabelle 2

Ergebnisse bakteriologischer Untersuchungen im Sylter Seebereich (Winter 1967/68 und Sommer 1968)

\begin{tabular}{|llcc|}
\hline Bakteriologische Kriterien & Region & Winter & Sommer \\
\hline \multirow{3}{*}{ Keimzahl pro ml } & freies Meer & 80 & 50 \\
& Weststrand & 830 & 650 \\
& Wattufer & 2600 & 3100 \\
Endo-Zahl pro $\mathrm{ml}$ & freies Meer & 0,3 & 0,2 \\
& Weststrand & 2 & 4,3 \\
& Wattufer, Südwatt & 8 & 31 \\
& Wattufer, Nordwatt & 28 & 41 \\
Coliformentiter (ml) & freies Meer & 100 & 100 neg \\
& Weststrand & $100-10$ & $100-10$ \\
& Wattufer & 1 & $10-1$ \\
\hline
\end{tabular}

wasserbakterien- und -nährstoffen ebenfalls im Sommer größer ist (die täglich geklärte Abwassermenge im Sommer ist mehr als doppelt so groß wie im Winter), so kann folgender Schluß gezogen werden: die ins Watt entwässernden Kläranlagen verursachen im Sommer eine erhöhte Keimzahl. Diese Keimzahl-Erhöhung folgt jedoch aus der Zunahme der organischen Substanz, die den Meeresbakterien zur Nahrung und damit zu schnellerer Vermehrung dient; sie scheint nicht auf direkter Zunahme der Konzentration überlebender Abwasserbakterien zu beruhen, denn die Konzentration der als ausschließlich terrigen bekannten coliformen Bakterien ist im Sommer nicht erhöht, sondern vermindert. Dieses wiederum ist eine Folge der im Sommer erhöhten Bakterizidie des Meerwassers. Nach diesen Befunden und Überlegungen kann festgestellt werden, daß die im Untersuchungszeitraum erreichte Abwasserbelastung des Sylter Wattenmeeres (vgl. Tab. 1) dessen biologische Selbstreinigungskraft nicht überstiegen hat. Abwasserbakterien wurden schnell abgetötet, die organische Substanz des Abwassers wurde von Meeresbakterien dissimiliert.

Mit einer Serie von Wasserproben aus der unmittelbaren Nähe des Rohrauslasses der Braderuper Kläranlage (Sommer 1968) sollte weiterhin festgestellt werden, wie hier die Keimzahl und die Coliformenkonzentration ist. Keimzahl- und Coliformentiterbefunde von zwölf Wasserproben dieses Bereiches zeigten, daß die Keimzahl in einem Umkreis von $150 \mathrm{~m}$ vom Rohrende über dem hygienisch kritischen Grenzwert liegt, während dies hinsichtlich des Coliformentiters im Umkreis von $250 \mathrm{~m}$ der Fall ist. Diese Befunde von der Braderuper Anlage mögen als pars pro toto auch für die anderen drei ins freie Watt entwässernden Anlagen - die alle einen geringeren Abwasserausstoß haben - gelten; sie lassen es geraten erscheinen, das Baden im Bereich von $250 \mathrm{~m}$ jederseits der Rohrauslässe sicherheitshalber zu verbieten.

Die Abhängigkeit der Abwasserbakterienkonzentration von den Gezeiten war Gegenstand weiterer Untersuchungen, deren nähere Beschreibung hier unterbleiben muß, da zu ihrem Verständnis topographische Abbildungen nötig wären. Mit Hilfe von stündlichen Probenahmen während einer Tide (12 Stunden von Niedrigwasser bis Niedrigwasser), die genau gleichzeitig von einem am Wattufer stehenden und von einem am gegenüberliegenden Weststrand stehenden Mitarbeiter geschöptt und sofort 
an Ort und Stelle zum Coliformentiter-Ansatz gebracht wurden, konnten im Gezeitenverlauf recht charakteristische Schwankungen der Titerhöhen in Beziehung zum Entnahmebereich beobachtet werden. Mit dieser Versuchsanordnung wurde je eine Probenserie im November 1967 bei Hörnum im Süden der Insel und im Juli 1968 bei List im Norden der Insel bearbeitet. Ihre Ergebnisse lassen den Schluß zu, daß das Wasser des Watts bei Ebbe aus dem Wattenbereich südwärts herausströmt, um bei Flut nicht nur teilweise wieder dorthin zurückgeschoben zu werden, sondern auch, um zu einem Teil an der Westküste der Insel längs des Badestrandes nordwärts zu gelangen. Die Messung der Coliformentiter konnte diesen Strömungsverlauf zeigen und weist darauf hin, daß bei Flut Bakterien aus dem abwasserführenden Wattenmeer in meßbarer Konzentration vor den Weststrand gelangen. Gezeitenabhängig bewegten sich die Coliformentiterwerte des Wattenmeeres zwischen 0,01 und 100, die des Weststrandwassers $z$ wischen 1 und 100. Abgesehen davon, daß zur Zeit weder hier noch dort die kritischen hygienischen Grenzwerte erreicht sind, verbietet doch diese erkennbare Proportionalität der Keimdichten, die Abwasserbelastung des Watts beliebig zu steigern, da schließlich einmal sogar am Hauptbadestrand der Insel im Westen eine hygienisch nicht zulässige Bakterienkonzentration die Folge sein könnte.

\section{DISKUSSION}

Hinsichtlich der Zuverlässigkeit der angewandten Maßstäbe für die Belastung des Seewassers mit Abwasserbakterien - sowohl anhand der ausführlich diskutierten Literatur als auch auf Grund eigener vergleichender Untersuchungen - ist folgendes festzustellen: Die Keimzahl ist bei Wasserproben, die aus der Brandung am Strand entnommen sind, absolut nicht repräsentativ für echte bakterielle Kontamination. Die Keimzahlen erwiesen sich als um so höher, je stärker die Brandung war. Das hatte auch schon Gunkel (1963) beobachtet, und er deutete den Sachyerhalt so, daß er bei Sturm eine Aufwirbelung des Sediments und seiner Bakterien sowie außerdem eine durch starken Seegang verursachte Zerschlagung von Bakterienaggregaten annahm, woraus eine scheinbar erhöhte Keimdichte des Meeres resultiert.

Auch in Gewässern, wo eine Aufwirbelung von Bakterien des Sediments nicht so nahe liegt, kann die Keimzahl nicht als sicher beweisend für unmittelbare Bakterieninvasion gelten, weil - wie oben berichtet - die Coliformenkonzentration (deren Beweiskraft für Abwasserbakterienbelastung unbestritten ist) in vielen Fällen nicht der Höhe der Keimzahl entspricht. Die Keimzahl sollte als Maß für die (z. B. abwasserbedingte) Nährstoffkonzentration im Seewasser gelten, nicht jedoch als Maß für die Abwasserbakteriendichte. Diese Forderung wird gestützt durch eine Beobachtung von RHEINHEIMER (1968), der aus einer Wasserproben-Serie von der Elbe zwischen Hamburg und Feuerschiff Elbe I Keimzahlansätze auf Meerwassernährboden einerseits und auf Süßwassernährboden andererseits ausgezählt und festgestellt hat, daß der Anteil der auf Süßwassermedium gewachsenen Keime an der auf Meerwassermedium gewachsenen Keimzahl um so kleiner war, je weiter seewärts die Wasserprobe entnommen worden war. Diese Beobachtung veranlaßte RHEINHEIMER, von einem im Meere stattfindenden „Ersatz“ der eingebrachten Süßwasserkeime durch Meerwasser- 
keime zu sprechen. Unter diesem Gesichtspunkt lassen sich auch die bei Sylt gewonnenen Befunde erklären: Die vielfach festgestellte und nach den oben genannten Befunden auch gegenüber den Coliformen wirksame Bakterizidie des Seewassers, welche im Sommer stärker ist als im Winter*, verhindert nicht, daß das Wattenmeer im Sommer eine höhere Gesamt-Keimzahl hat als im Winter. Warum nicht? Es handelt sich um eine Zunahme der autochthonen Meeresbakterien infolge der zur Sommerzeit vermehrten organischen Substanzen im Wattenwasser. Bedenkt man, daß diese Vermehrung abbaufähiger Substanzen teilweise der Abwasserbelastung zuzuschreiben ist, so wird man eine Vermehrung der Keimzahl in einem solchen Wasser geradezu begrüßen mïssen, da sie zeigt, daß die biologische Selbstreinigungskraft des Wassers sich einer Zunahme der Abwasserbelastung anpassen konnte.

Folgende Schlußfolgerungen können gezogen werden:

(a) Ein Gewässer, das einen hohen Gehalt an coliformen Bakterien hat, muß man als abwasserbelastet bezeichnen, und es ist von einem bestimmten Grenzwert an zum Baden ungeeignet, weil die coliformen Keime als Indikatoren dafür gelten, daß auch menschenpathogene Bakterien im gleichen Wasser enthalten sein können.

(b) Zeigt dieses Gewässer gleichzeitig eine entsprechend hohe Gesamt-Keimzahl, so sollte man die Abwasserbelastung als kompensiert betrachten; die Verunreinigung bleibt in einem umschriebenen Bereich.

(c) Zeigt dieses Gewässer eine der Coliformenkonzentration entsprechende Gesamt-Keimzahl nicht, so muß man es als mit Abwasser überlastet bezeichnen und es besteht die Gefahr, daß die Verunreinigung diffus wird. Das Eintreten einer solchen Dekompensation der Klärkraft des Meeres ist z. B. dann zu befürchten, wenn im Abwasser aus Industrie und Haushalten giftige Substanzen enthalten sind, die in der Lage sind, das Wachstum der Meeresbakterien und damit die biologische Selbstreinigungskraft des Meeres zu behindern. Eine im Verhältnis zur AbwasserbakterienKonzentration (Coliformen-Titer) zu niedrige Gesamt-Keimzahl wäre demnach als alarmierendes Symptom zu betrachten.

\section{ZUSAMMENFASSUNG}

1. Der Gehalt an Bakterien, speziell der coliformen Abwasserbakterien des Meerwassers, wurde im Bereich der Insel Sylt in den Jahren 1967/68 untersucht.

2. Keimzahl und Colititer der Wasserbereiche um Sylt liegen weit unterhalb der von den hygienischen Aufsichtsbehörden als zulässig anerkannten Höchstwerte mit Ausnahme der Bereiche von ca. $500 \mathrm{~m}$ Breite beiderseits der Auslässe, die das Abwasser der in das Wattenmeer entwässernden Kläranlagen ableiten.

"Im Wasser am Sylter Weststrand, wo ein direkter Einfluß von Abwasserbakterien ja nicht besteht, konnte der Verfasser folgende Beobachtung über das im Jahresgang wechselnde Verhalten der Bakterien machen: Entsprechend dem Vorgehen von RHEINHEmger wurden aus 105 Wasserproben parallele Keimzahlansätze auf Meerwasser- und auf Sußßwassernährboden ausgezählt. Dabei zeigten die Proben der Wintermonate einen Anteil der auf Süßwassernährboden angewachsenen Keime von $63 \%$, die Proben der Sommermonate dagegen
zeigten nur einen Anteil von $18 \%$. 
3. Die Keimzahl ist am Ufer des Wattenmeeres etwa dreimal höher als am Weststrand, am Weststrand etwa zehnmal höher als im uferferneren Meerwasser westlich Sylt. Der Coliformentiter unterscheidet sich in den drei Wasserbereichen jeweils um eine Stufe, d. h. am Wattufer ist die mittlere Coliformen-Konzentration etwa zehnmal höher als am Weststrand, am Weststrand etwa zehnmal höher als in der offenen See.

4. Es besteht eine Abhängigkeit der Bakterienkonzentration von den Gezeiten. Am Weststrand wurden die höchsten Coliformen-Konzentrationen bei Flut gefunden, im Wattenmeer bei Ebbe. Es wird gefolgert, daß die Kontamination des Wattenwassers mit Abwasserbestandteilen vermittels des Gezeitenstromes auch das Wasser an der Westseite der Insel (Hauptbadestrand) beeinflußt.

5. Es betehen deutliche jahrezeitliche Unterschiede der Bakterienkonzentration in den drei genannten Wasserbereichen. Die Keimzahl ist im Sommer in der freien See und am Weststrand niedriger als im Winter. Die Coliformen-Konzentration ist im Sommer in allen Bereichen niedriger als im Winter. Die im Sommer wegen des Fremdenverkehrs stark erhöhte Abwasserbelastung des Sylter Wattenmeeres wird offenbar sehr gut kompensiert dadurch, daß das Seewasser im Sommer eine größere Selbstreinigungskraft besitzt als im Winter.

6. Die Wasserproben des Weststrandes, die mit je zwei verschiedenen Nährböden auf ihre Keimzahl hin untersucht wurden, zeigten einen charakteristischen jahreszeitlichen Unterschied der Bakterienqualität: Unter Zugrundelegung der auf Seewassernährboden erzielten Keimzahl (als $100 \%$ ) betrug die auf Süßwassernährboden erzielte Keimzahl im Winter $63 \%$, im Sommer dagegen $18 \%$. Das weist darauf hin, daß terrigene (auf Süßwassernährboden vermehrungsfähige) Bakterien im Sommer eine kürzere Überlebenszeit haben als im Winter.

Danksagungen. Diese Arbeit ist ein Auszug aus einer medizinischen Dissertation (PeTERs 1970), die in den Jahren 1967 und 1968 am Institut für Bioklimatologie und Meeresheilkunde der Universität Kiel (in Westerland/Sylt) auf Anregung von Professor Dr. med. U. JEsser angefertigt wurde. Ihm vor allem gilt der Dank des Verfassers, ferner der Biologischen Anstalt Helgoland, dem Institut für Meereskunde an der Universität Kiel und dem HygieneInstitut der Universität Kiel für wesentliche Förderung der Arbeit.

\section{ZITIERTE LITERATUR}

Carlson, S., 1966. Zur Hygiene der Freibadegewässer und öffentlichen Schwimmbäder. Bundesgesundheitsbl. 12, 1969.

Carluccr, A. F. \& Pramer, D., 1959. An evaluation of factors affecting the survival of Escherichia coli in sea water. Appl. Microbiol. 8, 243-255.

Deutsche Einheitsverfahren zur Wasser-, AbWasser- und Schlammuntersuchung, 1960. Hrsg, von der Fachgruppe Wasserchemie in der Gesellschaft Deutscher Chemiker. 3. Aufl. Verl. Chemie, Weinheim.

GunkEL, W., 1963. Daten zur Bakterienverteilung in der Nordsee. Veröff. Inst. Meeresforsch. Bremerh. (Sonderbd) 3, 80- 89 .

- \& Rhernheimer, G., 1968. Bakterien. In: Methoden der meeresbiologischen Forschung. Hrsg. von C. Schlieper. Fischer, Jena, 142-157.

HrCKEL, W. \& GUNKEL, W., 1968. Untersuchungen äber die Häufigkeit der Bakterien in der obersten Sedimentschicht der Deutschen Bucht in Beziehung zu den Substrateigenschaften. Helgoländer wiss. Meeresunters. 18, 213-231. 
KAYSER, H., 1968. Hauptquellen häuslicher Abwässer und deren Bedeutung für die Verunreinigung der Nordsee. Helgoländer wiss. Meeresunters. 17, 25-43.

Peters, J., 1970. Hygienisch-bakteriologische Untersuchungen des Küsten-Meerwassers im Bereich der Insel Sylt. Med. Diss., Univ. Kiel.

Rhernheimer, G., 1968. Die Bedeutung des Elbe-Ästuars für die Abwasserbelastung der südlichen Nordsee in bakteriologischer Sicht. Helgoländer wiss. Meeresunters. 17, 445-454.

SchUbert, R., 1956. Die coliformen Bakterien in der Wasserdiagnostik und ihre Differenzierungen. Z. Hyg. InfektKrankh. 142, 476-486.

VACCARO, R. F. \& Briggs, M. P., 1950. Viability of Escherichia coli in sea water. Am. J. publ. Hlth 40, 1257-1266.

WeYLAND, H., 1967. Ober die Verbreitung von Abwasserbakterien im Sediment des WeserAstuars. Veröff. Inst. Meeresforsch. Bremerh. 10, 173-182.

Anschrift des Autors: Dr. J. Peters

Städtisches Krankenhaus

2982 Norderney

Deutschland (BRD) 